\title{
Targeted therapy in pulmonary veno- occlusive disease: time for a rethink?
}

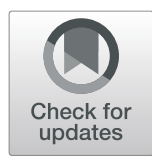

Qin Luo ${ }^{\dagger}$, Qi Jin ${ }^{\dagger}$, Zhihui Zhao, Qing Zhao, Xue Yu, Lu Yan, Yi Zhang, Changming Xiong and Zhihong Liu* (D)

\begin{abstract}
Background: Pulmonary veno-occlusive disease (PVOD) is a rare condition with poor prognosis, and lung transplantation is recommended as the only curative therapy. The role of pulmonary arterial hypertension targeted therapy in PVOD remains controversial, and long-term effects of targeted therapy have been rarely reported. This study aims to retrospectively evaluate the role of targeted therapy in PVOD patients and the long-term outcome.

Methods: PVOD patients with good responses to targeted therapies were analyzed, and data pre- and posttargeted therapies were compared. An overview of the effects of targeted therapies on PVOD patients was also conducted.

Results: Five genetically or histologically confirmed PVOD patients received targeted therapies and showed good responses. Their mean pulmonary arterial pressure by right heart catheterization was $62.0 \pm 11.7 \mathrm{mmHg}$. Two receiving monotherapy got stabilized, and three receiving sequential combination therapy got improved, cardiac function and exercise capacity significantly improved after treatments. No pulmonary edema occurred. The mean time from the first targeted therapy to the last follow up was 39.3 months, and the longest was 9 years. A systematic review regarding the effects of targeted therapies on PVOD patients indicated majorities of patients got hemodynamics or 6-min walk distance improved, and $26.7 \%$ patients developed pulmonary edema. The interval from targeted drugs use to death ranged from 71 min to over 4 years.

Conclusions: Cautious use of targeted therapy could safely and effectively improve or stabilize hemodynamics and exercise capacity of some patients without any complications. PVOD patients could live longer than expected.
\end{abstract}

Keywords: Pulmonary veno-occlusive disease, Pulmonary arterial hypertension, Targeted therapy

\section{Background}

Pulmonary veno-occlusive disease (PVOD), a subgroup of pulmonary arterial hypertension $(\mathrm{PAH})$, is a rare and devastating condition histologically characterized by occlusion of pulmonary veins and venules with widespread fibrous intimal thickening and patchy capillary proliferation. Although PVOD shares similar clinical features with idiopathic PAH (IPAH), it progresses more rapidly even while on therapy and carries a worse prognosis with a dismal 1-year mortality rate of $72 \%$ [1].

Targeted therapies involving prostacyclin, endothelin-1 and nitric oxide signaling pathways have remarkably improved the prognosis of $\mathrm{PAH}$ patients, nevertheless, their roles in PVOD remain controversial for lifethreatening drug-induced pulmonary edema. Only a few studies reported the effectiveness of vasodilators in PVOD without severe complications [2, 3]. It is currently recommended once PVOD is suspected, lung transplantation, the only curative therapy, should be considered as soon as possible [4]. In this study, we retrospectively analyzed five genetically or histologically confirmed PVOD patients with good responses to PAH-targeted drugs and no pulmonary edema, and shared our experience in the management and treatment of PVOD.

\footnotetext{
* Correspondence: zhihongliufuwai@163.com

${ }^{+}$Qin Luo and Qi Jin contributed equally to this work.

Center for Pulmonary Vascular Diseases, Fuwai Hospital, National Center for Cardiovascular Diseases, Chinese Academy of Medical Sciences and Peking Union Medical College, 167 Beilishi Road, Xicheng District, Beijing 100037, China
}

\section{Methods \\ Patients}

We retrospectively reviewed clinical data and outcomes from five PVOD patients hospitalized in the Center for 
Pulmonary Vascular Diseases (Fuwai Hospital, National Center for Cardiovascular Diseases, Chinese Academy of Medical Sciences and Peking Union Medical College, Beijing) between May 2009 and March 2018. PVOD was histologically confirmed by extensive involvement of pulmonary veins and venules with fibrous thickening of the intima on lung explants obtained after lung transplantation, or was clinically diagnosed if all following criteria were met: precapillary pulmonary hypertension by right heart catheterization (RHC), presence of two or more radiological characteristics of PVOD on chest highresolution computed tomography (HRCT) (interlobular septal thickening, centrilobular ground-glass opacities, and mediastinal lymph node enlargement), low diffusing capacity for carbon monoxide, and mutations of the eukaryotic translation initiation factor 2 alpha kinase 4 (EIF2AK4) gene [5]. IPAH was defined by a mean pulmonary arterial pressure (mPAP) $\geq 25 \mathrm{mmHg}$ at rest with pulmonary capillary wedge pressure $\leq 15 \mathrm{mmHg}$ and pulmonary vascular resistance (PVR) $>3$ Wood units, without known causes (connective tissue diseases, HIV infection, portal hypertension, congenital heart diseases and schistosomiasis), as we previously mentioned [6-8]. Good response to PAH targeted therapy was defined as improvement in New York Heart Association Functional Class (NYHA FC) with increased 6-min walk distance (6MWD), or stable condition without any deterioration of NYHA FC and 6MWD within 6 months. Signed written informed consents were obtained from all patients.

\section{Hemodynamic measurements}

Transthoracic doppler echocardiography was routinely performed on admission and at every follow-up, right ventricular end-diastolic diameter (RVED), left ventricular end-diastolic diameter (LVED), tricuspid annular plane systolic excursion (TAPSE), systolic pulmonary artery pressure (sPAP), left ventricular ejection fraction (LVEF) and pericardial effusion were documented, sPAP was estimated by tricuspid regurgitation velocity (TRV) and right atrium pressure (RAP), $S P A P=4 T^{2} V^{2}+R A P$. Hemodynamic evaluation by RHC was performed at baseline in all patients as we previously reported $[6,9]$. RHC was performed by experienced physicians during hospitalization, and hemodynamic data including mixed venous oxygen saturation $\left(\mathrm{SvO}_{2}\right)$, mean $\mathrm{RAP}$ (mRAP), right ventricular systolic pressure (RVSP), SPAP, mPAP, total pulmonary resistance (TPR), cardiac output (CO) and cardiac index $(\mathrm{CI})$ were recorded.

\section{Clinical and functional assessment}

Baseline data including sex, age, body mass index (BMI), symptom and signs, and medical history after initial admission were recorded. HRCT and pulmonary function tests were blindly performed and analyzed by experienced radiologists and medical technologists, and aforementioned radiological features, diffusing lung capacity of carbon monoxide (expressed as DLCO \% pred), and DLCO/ alveolar volume (expressed as DLCO/VA \% pred) were recorded. NYHA FC, cardiothoracic ratio by chest X-ray, hemodynamic data by echocardiography and RHC, arterial blood gases, complete blood counts, renal and liver function tests, N-terminal prohormone brain natriuretic peptide (NT-proBNP), and cardiopulmonary exercise testing measurements pre- and post- PAH-targeted therapies were detailly reviewed. Data after targeted therapies were obtained when patients achieved the best values for LVEF by echocardiography or cardiac index by RHC [10]. Screening for EIF2AK4 mutations was performed by Novogene Corporation, Beijing, China. Time from the first use of targeted therapy to the last follow up (April 2019) was described as survival time.

\section{Medical therapies}

Dosage and administration of anticoagulants, diuretics, digoxin and PAH-targeted drugs including endothelin receptor antagonists (ERAs: bosentan, ambrisentan, macitentan), phosphodiesterase type 5 inhibitors (PDE5is: sildenafil, tadalafil), the soluble guanylate cyclase stimulator (riociguat), prostanoids (beraprost, iloprost, epoprostenol, treprostinil), and selective prostacyclin receptor agonist (selexipag) were detailly reviewed. For PVOD patients in NYHA FC III/IV, the intravenous infusion rate of treprostinil was initiated at $1.25 \mathrm{ng} / \mathrm{kg} / \mathrm{min}$, and was adjusted in increments of $1.25-2.5$ $\mathrm{ng} / \mathrm{kg} / \mathrm{min}$ per day later. If not tolerated, the infusion rate was gradually reduced.

\section{Systematic review}

All studies or case reports in English regarding patients with PVOD receiving PAH-targeted drugs were selected. Inclusion criteria were as follows: a. Patients were genetically or histologically diagnosed with PVOD; b. Patients with PVOD received above PAH-targeted drugs; c. At least one of mPAP, PVR, CO, CI and 6MWD pre- and post- PAH-targeted therapies was documented, if not available, dosage of targeted drugs and outcomes (6MWD and survival time) had to be included. All selected articles were screened by two independent reviewers, any discordances were resolved by further discussion. Data including demographics and hemodynamic measurements by RHC (mPAP, PVR, CO and $\mathrm{CI}$ ), drug name and dosage, outcomes and complications (6MWD, time from targeted drug use to death and pulmonary edema) were extracted.

\section{Statistical analysis}

Statistical analysis was performed using SPSS version 23.0 (IBM Corp., Armonk, NY, USA). Results were presented as mean \pm standard deviation for continuous 
variables. Differences pre- and post- PAH-targeted therapies were compared using paired t-test and drawn by GraphPad Prism Version 5.0 (GraphPad Software Inc., San Diego, CA, USA). A two-sided $P<0.05$ was considered statistically significant.

\section{Results}

\section{Baseline characteristics}

Between May 2009 and March 2018, five patients with PVOD (34.2 \pm 5.0 years) responding well to targeted therapies in our center were collected (Table 1). All patients complained of chest tightness and/or shortness of breath, and only one patient presented with edema of lower extremities on admission which disappeared after diuretic therapy. At least two of characteristic HRCT features including interlobular septal thickening, ground glass opacities and enlarged mediastinal lymph nodes were found in each subject. Moreover, severe diffusion dysfunction with a decreased DLCO \% pred (31.1 \pm 2.9\%) was observed. EIF2AK4 gene mutation, a cause of heritable PVOD, was found in all cases (Fig. 1, Table 1). Patient 5 was misdiagnosed with IPAH and received PAH-targeted therapies for over 9 years, and he was confirmed as PVOD by biopsy of lung explants obtained after lung transplantation. Three patients were exposed to smoking, a potential risk factor strongly associated with PVOD [1]. Time from onset to admission ranged from 1 to 84 months.
Clinical variables pre- and post- targeted therapies

Clinical variables pre- and post- targeted therapies were shown in Additional file 1: Table S1. Three patients were in NYHA FC III/IV on admission and got improved to NYHA FC II after treatments. RVED decreased significantly compared to that on admission (36.0 \pm 3.8 vs $29.4 \pm 3.2 \mathrm{~mm}, P<0.05)$. sPAP estimated by echocardiography and mPAP measured by RHC were $86.8 \pm 20.5$ $\mathrm{mmHg}$ and $62.0 \pm 11.7 \mathrm{mmHg}$ respectively. For some reasons such as economic issues, RHC was not performed in some patients post-targeted therapies. NTproBNP and 6MWD were both remarkably improved in Patient 1/3/5 after treatments (Additional file 1: Table S1; Fig. 2). The mean time from the first use of targeted therapy to the last follow up was 39.3 months, four are still in good condition, the last was re-hospitalized several times for alcohol intoxication or volume overload during 9 years and underwent lung transplantation in May 2018, and histopathologic examination confirmed intimal remodeling of veins and venules.

\section{General treatment and PAH-targeted therapy}

Table 2 summarizes the medical therapies for our patients. Four were anticoagulated with warfarin. All took diuretics, three were treated with at least two kinds of diuretics. All received targeted therapies, two were given monotherapy, two with sequential dual combination therapy (tadalafil or sildenafil combined with treprostinil), one

Table 1 Basic characteristics of patients with PVOD

\begin{tabular}{|c|c|c|c|c|c|}
\hline Patient number & 1 & 2 & 3 & 4 & 5 \\
\hline Sex & $M$ & $\mathrm{~F}$ & M & M & M \\
\hline Age ranges (year) & $35-40$ & $35-40$ & $30-35$ & $32-37$ & $25-30$ \\
\hline BMI $\left(\mathrm{kg} / \mathrm{m}^{2}\right)$ & 18.0 & 18.7 & 21.9 & 22.4 & 15.5 \\
\hline Chest tightness / Shortness of breath & Yes & Yes & Yes & Yes & Yes \\
\hline Edema of lower extremities & No & No & Yes & No & No \\
\hline \multicolumn{6}{|l|}{ HRCT } \\
\hline Interlobular septal thickening & Yes & Yes & No & Yes & Yes \\
\hline Ground glass opacities & Yes & Yes & Yes & Yes & Yes \\
\hline Enlarged mediastinal lymph nodes & No & No & Yes & No & No \\
\hline EIF2AK4 mutation & c.2488C > T; c.989_990del & c.2965C > T; c.4724T>C & c. $1948 C>T$ & c.3460A > T; c.4736 T > C & c.4414_4417del \\
\hline \multicolumn{6}{|l|}{ Medical history } \\
\hline Smoking & Yes & No & No & Yes & Yes \\
\hline Drinking & No & No & No & Yes & No \\
\hline Acute coronary disease & No & No & No & No & No \\
\hline Hypertension & No & No & No & No & No \\
\hline Hyperlipemia & No & No & No & No & No \\
\hline Diabetes & No & No & No & No & No \\
\hline Obstructive sleep apnea & No & No & No & No & No \\
\hline Time from onset to admission (month) & 72 & 1 & 84 & 60 & 6 \\
\hline
\end{tabular}



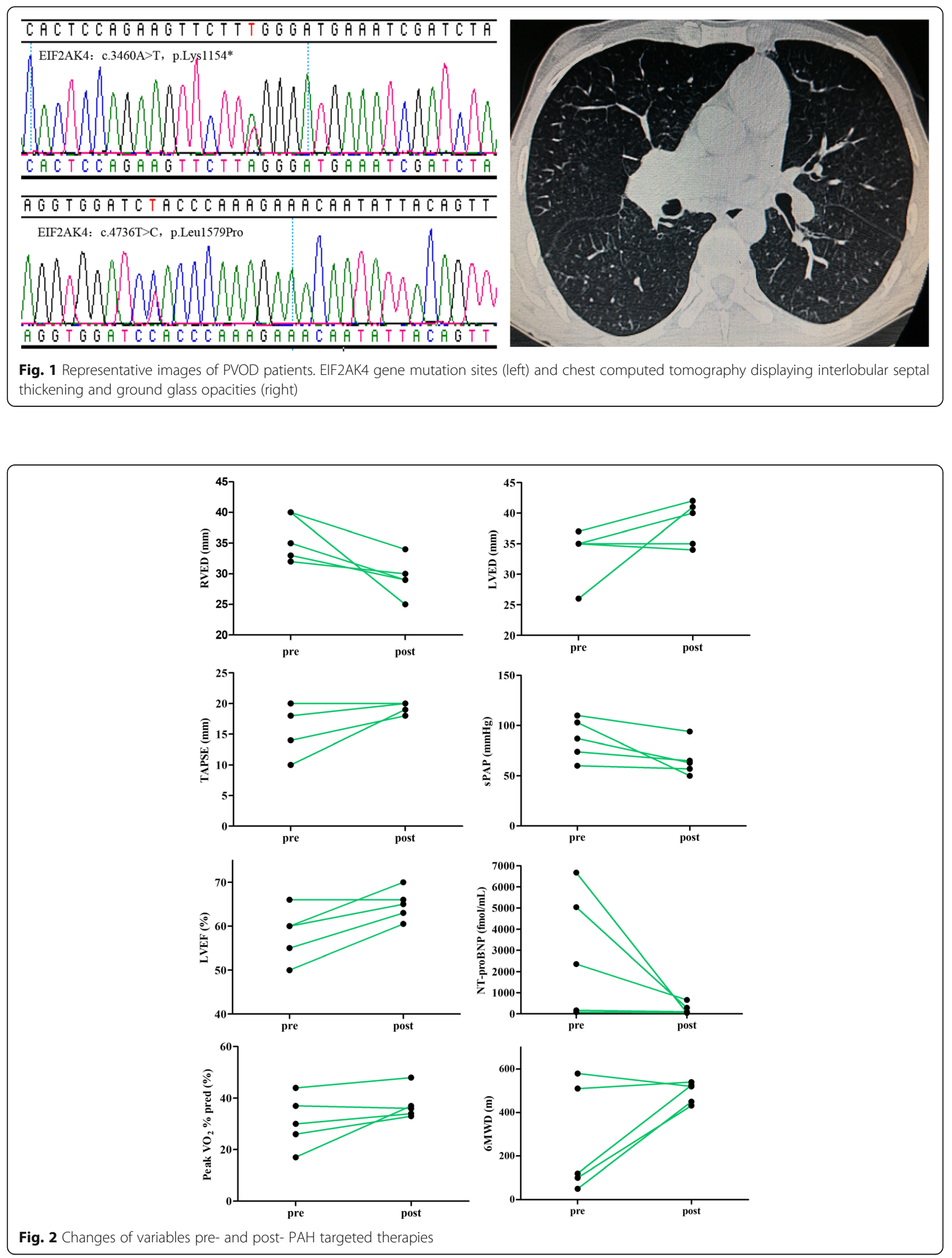
Table 2 General treatment and PAH targeted therapy in patients with PVOD

\begin{tabular}{|c|c|c|c|c|c|}
\hline Patient number & 1 & 2 & 3 & 4 & 5 \\
\hline Warfarin & $2.25 \mathrm{mg}, \mathrm{po}, \mathrm{qod}$ & $2.25 \mathrm{mg}, \mathrm{po}, \mathrm{qd}$ & No & $5 \mathrm{mg}, \mathrm{po}, \mathrm{qd}$ & $2 \mathrm{mg}, \mathrm{po}, \mathrm{qd}$ \\
\hline \multicolumn{6}{|l|}{ Diuretics } \\
\hline Spironolactone & No & $20 \mathrm{mg}, \mathrm{po}, \mathrm{qd}$ & $2 \mathrm{No}$ & $20 \mathrm{mg}, \mathrm{po}, \mathrm{qd}$ & $20 \mathrm{mg}, \mathrm{po}, \mathrm{qd}$ \\
\hline Furosemide & $40 \mathrm{mg}, \mathrm{po}, \mathrm{qod}$ & No & $20 \mathrm{mg}, \mathrm{po}, \mathrm{qod}$ & No & $20 \mathrm{mg}, \mathrm{po}, \mathrm{qod}$ \\
\hline Torsemide & $20 \mathrm{mg}, \mathrm{po}, \mathrm{qod}$ & No & $10 \mathrm{mg}, \mathrm{po}, \mathrm{qod}$ & No & $10 \mathrm{mg}, \mathrm{po}, \mathrm{qod}$ \\
\hline Digoxin & $0.125 \mathrm{mg}, \mathrm{po}, \mathrm{qd}$ & No & $0.25 \mathrm{mg}, \mathrm{po}, \mathrm{qd}$ & No & $0.125 \mathrm{mg}, \mathrm{po}, \mathrm{qd}$ \\
\hline \multicolumn{6}{|l|}{ Targeted therapies } \\
\hline ERAs & No & No & No & No & Ambrisentan, 10 mg, po, qd \\
\hline PDE5is & Tadalafil, $10 \mathrm{mg}$, po, qd & $\begin{array}{l}\text { Tadalafil, } 10 \mathrm{mg} \text {, } \\
\text { po, qd }\end{array}$ & $\begin{array}{l}\text { Sildenafil, } 20 \text { mg, po, } \\
\text { tid }\end{array}$ & $\begin{array}{l}\text { Sildenafil, } 20 \text { mg, } \\
\text { po, tid }\end{array}$ & Sildenafil, 20 mg, po, tid \\
\hline Prostanoids & $\begin{array}{l}\text { Treprostinil, iv, } 15.25 \\
\mathrm{ng} / \mathrm{kg} / \mathrm{min}\end{array}$ & No & $\begin{array}{l}\text { Treprostinil, iv, } 17.5 \mathrm{ng} / \\
\mathrm{min} / \mathrm{kg}\end{array}$ & No & $\begin{array}{l}\text { lloprost, } 1 \mathrm{ml} \text {, inh, q3h; Treprostinil, iv, } \\
20 \mathrm{ng} / \mathrm{min} / \mathrm{kg}\end{array}$ \\
\hline
\end{tabular}

ERAs Endothelin receptor antagonists, PDE5is Phosphodiesterase type 5 inhibitors

with sequential quadruple combination therapy. All responded well to targeted therapies without pulmonary edema occurrence (See Additional file 1: Figure S1), no symptoms such as hemoptysis or pink frothy sputum occurred among our patients when given targeted drugs, NT-proBNP levels decreased, and their arterial oxygen saturation and DLCO got improved, some patients had no supplemental oxygen requirement and maintained oxygen saturation $>95 \%$ after treatments. Notable clinical and hemodynamic improvements with increased cardiac function and 6MWD were observed in three patients in NYHA FC III/IV, and two patients in NYHA FC II treated with tadalafil or sildenafil achieved stabilized condition for over 36 and 13.3 months respectively. Patient 5 received inhaled iloprost at his first onset in May 2009, and sildenafil was added on since July 2009. In June 2013, ambrisen$\tan$ was sequentially combined, and treprostinil was added from September 2016 till his transplantation in May 2018.

\section{Systematic review of patients with PVOD receiving PAH- targeted drugs}

No prospective cohort studies or randomized controlled trials have been performed by now. Sixteen case reports and one retrospective study between 1989 and 2018 met the inclusion criteria (Additional file 1: Table S2) [2, 11-26]. A total of 30 patients with PVOD receiving PAH-targeted drugs during their hospitalizations were reported, and 16 out of them (53.3\%) were male. Sixteen patients received monotherapy $[2,11-17,19,22]$, the commonest targeted drug used for these patients was epoprostenol (75\%), and $12 \mathrm{pa-}$ tients were treated with sequential dual combination therapy $[2,18,21,24-26]$, one with initial dual combination therapy [2], one with sequential triple combination therapy, bosentan $125 \mathrm{mg}$ bid stabilized his condition for 7 months, sildenafil $40 \mathrm{mg}$ tid as an add-on therapy enabled remarkable clinical stabilization with a 6MWD of $560 \mathrm{~m}$, then a low dose of epoprostenol $(1-2 \mathrm{ng} / \mathrm{kg} / \mathrm{min})$ was added for declined exercise capacity but was stopped due to deterioration of oxygen saturation, sequential iloprost $2.5 \mu \mathrm{g}$ q4h maintained his status till double lung transplantation [23]. Sildenafil was demonstrated to be effective and safe [17], and it is one of the most frequently used drugs in combined therapy for PVOD patients [18, 21, 23-26], those receiving sildenafil as monotherapy [17] or combined therapy [18, 21, 23, 25, 26] almost survived more than 1 year. Pulmonary edema following targeted drugs occurred in eight patients $(26.7 \%)[2,12,13,16$, $19,21-23]$, and epoprostenol seemed to induce pulmonary edema more frequently. Gratifyingly, some patients got hemodynamics or 6MWD improved more or less even though pulmonary edema happened [2, 12, 16, 19, 22, 23], and one of them even lived to 4 years after diagnosis [23]. The time from targeted drugs use to death ranged from 71 min to more than 4 years.

\section{Discussion}

PVOD is a rare cause of pulmonary hypertension, and is currently classified as a subgroup of PAH. The exact prevalence of PVOD remains unknown, because many cases are probably misdiagnosed as IPAH due to similar clinical and hemodynamic features and lack of histological or genetic confirmation. It was estimated PVOD accounted for around 10\% cases of IPAH [4]. Unlike IPAH which has a female predominance, PVOD seems to affect men and women equally [27]. Its molecular pathogenesis remains unclear, risk factors such as genetic factors, chemicals and chemotherapies, autoimmunity and inflammation, and cigarette smoking exposure have been reported to be associated with the development of PVOD $[1,5]$, and three of our patients got tobacco exposure which caused endothelial dysfunction and induced vascular remodeling in animal models of pulmonary hypertension.

The pathological feature of PVOD is characterized by diffuse intimal fibrosis of the small veins and venules. 
Histopathological examination remains the gold standard for a definitive diagnosis of PVOD, however, lung biopsy is contraindicated due to unacceptable high risk of bleeding. A combination of clinical findings, low diffusing capacity for carbon monoxide and characteristic signs on chest HRCT is recommended to diagnose PVOD [4]. All our patients presented with dyspnea, severe diffusion dysfunction with DLCO/ VA \% pred < $55 \%$, and decreased exercise capacity, and had at least two radiological signs of PVOD described on HRCT. $E I F 2 A K 4$ gene was identified as the major gene in the families with heritable PVOD in 2014 [28], and identification of a biallelic EIF2AK4 mutation is practically enough to diagnose PVOD even without histological confirmation [4]. A recent study reported a patient carrying biallelic EIF2AK4 gene mutation displayed good response to $\mathrm{PAH}$-targeted therapy and was alive for over 3 years [26], similarly, all our patients were detected with biallelic EIF2AK4 mutations and showed good responses, but the prognoses of patients with biallelic mutations in EIF2AK4 varied [29], indicating possibly favorable effects of PAH-targeted drugs in patients harboring specific EIF2AK4 gene mutations.

PVOD prognosis is worse than other subtypes of PAH with a $72 \%$ mortality within 1 year after diagnosis [15]. PAH-targeted therapy prominently improved the outcome of PAH patients, yet evidences on the use of PAHtargeted therapy in PVOD are still weak and conflicting, it is generally recognized that targeted therapy can be harmful and occasionally fatal in PVOD for severe complications, thus vasodilators are only recommended as a bridge to transplantation. However, our study conferred different perspectives, the mean time from targeted therapy to last follow up was 39.3 months, one patient (Patient 5) was previously misdiagnosed with IPAH and received sequential combination therapies, biallelic EIF2AK4 mutations were detected in June 2017, and PVOD was finally considered when combined with his clinical characteristics. However, lung transplantation was postponed due to his unwillingness till May 2018. To the best of our knowledge, the longest duration under monotherapy (beraprost) among PVOD patients was over 15 years after initial admission [30], and our patient had the longest 9-year duration under combined therapy. Additionally, some cases also reported over 2year survival under targeted therapy [15, 16, 19, 23, 26], all of which forced us to rethink the role of PAHtargeted therapy in PVOD, we question is it really true that PVOD patients will deteriorate quickly and die within 1 year? Is lung transplantation still the only curative approach? Can targeted therapy only serve as a bridge to transplantation? Can we decide not to use targeted therapy just for fear of pulmonary edema? A recent systematic review regarding the efficacy and safety of vasodilators in PVOD patients showed vasodilators could effectively improve PVR, 6MWD and survival in some cases, but correlated with the risk of pulmonary edema in many cases [3]. Even pulmonary edema occurred, some patients could still tolerate and had startling prognoses for more than 2 years $[16,19,23]$. Long term clinical response to vasodilators is rarely reported, in our clinical investigation, PAH-targeted therapy can effectively improve cardiac function and 6MWD or long-termly stabilize the status at least for certain PVOD patients under large doses of diuretics without any pulmonary edema. Gene mutation screening may be considered, especially for those in their early stage, responses to targeted therapies at that time can be tested without leading to lethal pulmonary edema, Patient 2 and 4 are the best examples. Large doses of diuretics should be used when PAH-targeted therapies were prescribed. Anticoagulation is currently controversial among PVOD patients and should be individually administrated. Patient 1 was anticoagulated in consideration of his medical history of antiphospholipid syndrome and venous thromboembolism. Considering a relatively low risk of bleeding, Patients $2 / 4$ received anticoagulation therapies before the results of gene detection came out. For Patient 3, he was admitted for the evaluation of lung transplantation in March 2018 and was genetically confirmed with PVOD, thus anticoagulation therapy was not prescribed. Patient 5 was previously misdiagnosed with IPAH, and therefore received anticoagulants for a long period.

Bosentan, an endothelin receptor antagonist, was reported to be effective in improving hemodynamics $[20,22,27]$, however, pulmonary edema occurred in some cases and the outcomes varied [21-23]. Macitentan was first proved to be beneficial for PVOD in 2016, and brought a clear improvement when combined with sildenafil [25]. Here in our study, we for the first time reported the good effects of tadalafil combined with or without treprostinil on PVOD (Patient 1/2), and also presented the second successful example of ambrisentan in treating PVOD (Patient 5). Sildenafil, a specific inhibitor of PDE5, may have a better safety profile due to its mild impact on pulmonary wedge pressure, chronic administration of sildenafil was effective in enhancing exercise capacity of PVOD patient [17], for our patients, we usually started with sildenafil or tadalafil, ambrisentan was sequentially added on if no obvious effects were observed. It was previously revealed pulmonary capillary pressure increased with low-dose prostacyclin but decreased with higher doses [12], indicating low-dose prostacyclin might cause pulmonary edema. A recent study demonstrated cautious application of epoprostenol at a high dose $(24.1 \pm 9.4 \mathrm{ng} / \mathrm{min} / \mathrm{kg})$ improved 
exercise capacity and increased cardiac index, and worked successfully as a bridge to lung transplantation [10]. Before using treprostinil for severe patients, intravenous iloprost for its short half-life period was firstly attempted in our clinical practice. Careful titration of treprostinil which was initiated at $1.25 \mathrm{ng} / \mathrm{kg} / \mathrm{min}$, and then adjusted in rapid increments of $1.25-2.5 \mathrm{ng} / \mathrm{kg} / \mathrm{min}$ per day later with necessary diuretics or inotropes, was proved to be safe and useful for our patients. Effectiveness of these targeted drugs on PVOD may be explained by vasodilating postcapillary vessels with higher doses. Initial dual combination therapy should be avoided due to highly possible pulmonary edema. Larger-scale studies with long-term follow-up should be carried out to confirm these findings.

Our study had several limitations. Five patients were included in this retrospective study, the sample size was relatively small. Besides, RHC was not conducted in some patients for safety and economic issues during follow-up, which could not best reflect the hemodynamic improvements under PAH-targeted therapy. Last but not the least, there is definitely a publication bias in PVOD literature since cases with good outcomes under targeted therapy have a higher probability of being published than those with dismal prognoses, moreover, we excluded studies with limited data in our systematic review, thus inevitably producing selection bias.

\section{Conclusions}

We applied PAH-targeted therapies to 5 PVOD patients and achieved good responses without any severe complications. Cautious application of PAH-targeted therapy could safely and effectively improve or stabilize hemodynamics and exercise capacity of some patients without pulmonary edema. PVOD patients could live longer than expected.

\section{Supplementary information}

Supplementary information accompanies this paper at https://doi.org/10. 1186/s12890-019-1031-3.

Additional file 1: Table S1. Clinical variables pre- and post- $\mathrm{PAH}$ targeted therapies. Table S2. Systematic review of patients with PVOD receiving $\mathrm{PAH}$ targeted drugs. Figure $\mathbf{S} 1$. Chest $\mathrm{X}$-ray and computed tomography pre- $(A, C)$ and post- $(B, D) P A H$ targeted therapy in Patient 3.

\footnotetext{
Abbreviations

6MWD: 6-min walk distance; BMI: Body mass index; Cl: Cardiac index; CO: Cardiac output; DLCONA: Diffusing lung capacity of carbon monoxide/ alveolar volume; EIF2AK4: Eukaryotic translation initiation factor 2 alpha kinase 4; ERAs: Endothelin receptor antagonists; HRCT: High resolution computed tomography; IPAH: Idiopathic PAH; LVED: Left ventricular enddiastolic diameter; LVEF: Left ventricular ejection fraction; MPAP: Mean pulmonary arterial pressure; mRAP: Mean RAP; NT-proBNP: N-terminal prohormone brain natriuretic peptide; NYHA FC: New York Heart Association Functional Class; PAH: Pulmonary arterial hypertension;

PDE5is: Phosphodiesterase type 5 inhibitors; PVOD: Pulmonary venoocclusive disease; PVR: Pulmonary vascular resistance; RAP: Right atrium
}

pressure; RHC: Right heart catheterization; RVED: Right ventricular enddiastolic diameter; RVSP: Right ventricular systolic pressure; sPAP: Systolic pulmonary artery pressure; $\mathrm{SVO}_{2}$ : Mixed venous oxygen saturation; TAPSE: Tricuspid annular plane systolic excursion; TPR: Total pulmonary resistance; TRV: Tricuspid regurgitation velocity

\section{Acknowledgements}

The abstract was presented at the 30th Great Wall International Congress of Cardiology, China Heart Society, and Beijing Society of Cardiology, held on October 10-13, 2019, at the China National Convention Center, Beijing, China. https://doi.org/10.15212/CVIA.2019.0021.

\section{Authors' contributions}

QL, QJ, ZZ and QZ collected the data. QL and QJ analyzed the data and drafted the manuscript. QL, QJ, XY, LY and YZ contributed to the systematic review. CX critically reviewed and revised the manuscript. ZL designed and revised the manuscript. All authors read and approved the final manuscript.

\section{Funding}

This work was supported by National Natural Science Foundation of China (81370326, 81641005), Beijing Municipal Science and Technology Project (Z181100001718200), National Precision Medical Research Program of China (2016YFC0905602) and Beijing Municipal Natural Science Foundation (7202168)

The funders had no role in the design of the study, the collection, analysis, and interpretation of data and in writing the manuscript.

Availability of data and materials

All data generated or analyzed during this study are included in this manuscript.

Ethics approval and consent to participate

The study was approved by the ethics committee of Fuwai Hospital and adhered to the Declaration of Helsinki.

Consent for publication

Not applicable.

\section{Competing interests}

The authors declare that they have no competing interests.

Received: 4 July 2019 Accepted: 12 December 2019

Published online: 19 December 2019

\section{References}

1. Montani D, Lau EM, Dorfmüller P, Girerd B, Jaïs X, Savale $L$, et al. Pulmonary veno-occlusive disease. Eur Respir J. 2016;47:1518-34.

2. Montani D, Jaïs X, Price LC, Achouh L, Degano B, Mercier O, et al. Cautious epoprostenol therapy is a safe bridge to lung transplantation in pulmonary veno-occlusive disease. Eur Respir J. 2009:34:1348-56.

3. Ogawa A, Sakao S, Tanabe N, Matsubara H, Tatsumi K. Use of vasodilators for the treatment of pulmonary veno-occlusive disease and pulmonary capillary hemangiomatosis: a systematic review. Respir Investig. 2018;57: 183-90

4. Galiè N, Humbert M, Vachiery JL, Gibbs S, Lang I, Torbicki A, et al. 2015 ESC/ ERS guidelines for the diagnosis and treatment of pulmonary hypertension. Eur Respir J. 2015:46:903-75.

5. Szturmowicz M, Kacprzak A, Szołkowska M, Burakowska B, Szczepulska E, Kuś J. Pulmonary veno-occlusive disease: pathogenesis, risk factors, clinical features and diagnostic algorithm - state of the art. Adv Respir Med. 2018; 86:131-41.

6. Tang Y, Yao L, Liu Z, Ma X, Luo Q, Zhao Z, et al. Effect of calcium channel blockers evaluated by cardiopulmonary exercise testing in idiopathic pulmonary arterial hypertension responding to acute pulmonary vasoreactivity testing. Pulm Pharmacol Ther. 2017:43:26-31.

7. Tang Y, Luo Q, Liu Z, Ma X, Zhao Z, Huang Z, et al. Oxygen uptake efficiency slope predicts poor outcome in patients with idiopathic pulmonary arterial hypertension. J Am Heart Assoc. 2017;6:e005037.

8. Tang Y, Yao L, Liu Z, Xie W, Ma X, Luo Q, et al. Peak circulatory power is a strong prognostic factor in patients with idiopathic pulmonary arteria hypertension. Respir Med. 2018;135:29-34. 
9. Yu X, Luo Q, Liu Z, Zhao Z, Zhao Q, An C, et al. Prevalence of iron deficiency in different subtypes of pulmonary hypertension. Heart Lung. 2018:47:308-13.

10. Ogawa A, Miyaji K, Yamadori I, Shinno Y, Miura A, Kusano KF, et al. Safety and efficacy of epoprostenol therapy in pulmonary veno-occlusive disease and pulmonary capillary hemangiomatosis. Circ J. 2012;76:1729-36.

11. Jones K, Higenbottam T, Wallwork J. Pulmonary vasodilation with prostacyclin in primary and secondary pulmonary hypertension. Chest. 1989;96:784-9.

12. Davis LL, de Boisblanc BP, Glynn CE, Ramirez C, Summer WR. Effect of prostacyclin on microvascular pressures in a patient with pulmonary venoocclusive disease. Chest. 1995;108:1754-6.

13. Palmer SM, Robinson LJ, Wang A, Gossage JR, Bashore T, Tapson VF. Massive pulmonary edema and death after prostacyclin infusion in a patient with pulmonary veno-occlusive disease. Chest. 1998;113:237-40.

14. Hoeper MM, Eschenbruch C, Zink-Wohlfart C, Schulz A, Markworth S, Pohl K et al. Effects of inhaled nitric oxide and aerosolized iloprost in pulmonary veno-occlusive disease. Respir Med. 1999;93:62-4.

15. Holcomb BW Jr, Loyd JE, Ely EW, Johnson J, Robbins IM. Pulmonary venoocclusive disease: a case series and new observations. Chest. 2000;118:1671-9.

16. Okumura H, Nagaya N, Kyotani S, Sakamaki F, Nakanishi N, Fukuhara S, et al. Effects of continuous IV prostacyclin in a patient with pulmonary venoocclusive disease. Chest. 2002:122:1096-8.

17. Barreto AC, Franchi SM, Castro CR, Lopes AA. One-year follow-up of the effects of sildenafil on pulmonary arterial hypertension and veno-occlusive disease. Braz J Med Biol Res. 2005;38:185-95.

18. Kuroda T, Hirota H, Masaki M, Sugiyama S, Oshima Y, Terai K, et al. Sildenafil as adjunct therapy to high-dose epoprostenol in a patient with pulmonary veno-occlusive disease. Heart Lung Circ. 2006;15:139-42.

19. Overbeek MJ, van Nieuw Amerongen GP, Boonstra A, Smit EF, VonkNoordegraaf A. Possible role of imatinib in clinical pulmonary venoocclusive disease. Eur Respir J. 2008;32:232-5.

20. Barboza CE, Jardim CV, Hovnanian AL, Dias BA, Souza R. Pulmonary venoocclusive disease: diagnostic and therapeutic alternatives. J Bras Pneumol. 2008;34:749-52.

21. Montani D, Jaïs X, Dorfmuller P, Simonneau G, Sitbon O, Humbert M. Goaloriented therapy in pulmonary veno-occlusive disease: a word of caution. Eur Respir J. 2009;34:1204-6.

22. Palazzini M, Manes A. Pulmonary veno-occlusive disease misdiagnosed as idiopathic pulmonary arterial hypertension. Eur Respir Rev. 2009;18:177-80.

23. Sourla E, Paspala A, Boutou A, Kontou P, Stanopoulos I, Pitsiou G. A case of pulmonary veno-occlusive disease: diagnostic dilemmas and therapeutic challenges. Ther Adv Respir Dis. 2013;7:119-23.

24. El-Gammal A, Alsudairi S, Alwohaibi R, Aldihan W, Alsufiani S, Fadel R, et al. Pulmonary Veno-occlusive disease: a case report and review of literature. Clin Case Rep Rev. 2016;2:1-4.

25. Chamorro Fernández Cl, Garcés Cabello P, Pérez Mateos R, Sánchez Soriano RM, Ferrando Siscar C, Quezada Loaiza CA. The first experience of pulmonary Veno-occlusive disease treatment with Macitentan and Sildenafil. Rev Esp Cardiol (Engl Ed). 2017;70:396-7.

26. Liang L, Su H, Ma X, Zhang R. Good response to PAH-targeted drugs in a PVOD patient carrying Biallelic EIF2AK4 mutation. Respir Res. 2018;19:192.

27. Montani D, Achouh L, Dorfmüller P, Le Pavec J, Sztrymf B, Tchérakian C, et al. Pulmonary veno-occlusive disease: clinical, functional, radiologic, and hemodynamic characteristics and outcome of 24 cases confirmed by histology. Medicine (Baltimore). 2008;87:220-33.

28. Eyries M, Montani D, Girerd B, Perret C, Leroy A, Lonjou C, et al. ElF2AK4 mutations cause pulmonary veno-occlusive disease, a recessive form of pulmonary hypertension. Nat Genet. 2014;46:65-9.

29. Montani D, Girerd B, Jaïs X, Levy M, Amar D, Savale L, et al. Clinical phenotypes and outcomes of heritable and sporadic pulmonary veno-occlusive disease: a population-based study. Lancet Respir Med. 2017:5:125-34.

30. Matsushita K, Kanna M, Yazawa T, Shimizu S, Nitta M, Takamizawa T, et al. Long-term survivor with pulmonary veno-occlusive disease. Circulation. 2012;125:e503-6.

\section{Publisher's Note}

Springer Nature remains neutral with regard to jurisdictional claims in published maps and institutional affiliations.

\section{Ready to submit your research? Choose BMC and benefit from:}

- fast, convenient online submission

- thorough peer review by experienced researchers in your field

- rapid publication on acceptance

- support for research data, including large and complex data types

- gold Open Access which fosters wider collaboration and increased citations

- maximum visibility for your research: over $100 \mathrm{M}$ website views per year

At $\mathrm{BMC}$, research is always in progress.

Learn more biomedcentral.com/submissions 